\title{
High-Content Screening of Human Primary Muscle Satellite Cells for New Therapies for Muscular Atrophy/Dystrophy
}

\author{
Lidia S. Nierobisz ${ }^{1}$, Bentley Cheatham², Benjamin M. Buehrer ${ }^{2}$ and Jonathan Z. Sexton ${ }^{1, *}$ \\ ${ }^{1}$ Biomanufacturing Research Institute and Technology Enterprise, Department of Pharmaceutical Sciences, North Caro- \\ lina Central University Durham, NC 27707, USA \\ ${ }^{2}$ ZenBio Inc. RTP, NC 27709, USA
}

\begin{abstract}
Myoblast proliferation and differentiation are essential for normal skeletal muscle growth and repair. Muscle recovery is dependent on the quiescent population of muscle stem cells - satellite cells. During muscle injury, satellite cells become mitotically active and begin the repair process by fusing with each other and/or with myofibers. Aging, prolonged inactivity, obesity, cachexia and other muscle wasting diseases are associated with a decreased number of quiescent and proliferating satellite cells, which impedes the repair process.

A high-content/high-throughput platform was developed and utilized for robust phenotypic evaluation of human primary satellite cells in vitro for the discovery of chemical probes that may improve muscle recovery. A 1600 compound pilot screen was developed using two highly annotated small molecule libraries. This screen yielded 15 dose responsive compounds that increased proliferation rate in satellite cells derived from a single obese human donor. Two of these compounds remained dose responsive when counter-screened in 3-donor obese superlot. The Alk-5 inhibitor LY364947, was used as a positive control for assessing satellite cell proliferation/delayed differentiation. A multivariate approach was utilized for exploratory data analysis to discover proliferation vs. differentiation-dependent changes in cellular phenotype. Initial screening efforts successfully identified a number of phenotypic outcomes that are associated with desired effect of stimulation of proliferation and delayed differentiation.
\end{abstract}

Keywords: High-content screening, LY364947, muscle atrophy, phenotypic high-content analysis and satellite cell proliferation.

\section{INTRODUCTION}

Decreased physical activity, obesity, aging and cachexia result in a decline in the quality of skeletal muscle tissue and its capacity for regeneration $[1,2]$. Skeletal muscle regenerative capacity is highly dependent on mitotic activity of a small population of satellite cells located between basal lamina and sarcolemma of the myofiber [3]. Satellite cells are mononuclear myogenic progenitor cells, which contribute to muscle growth and restoration [4]. Post-natal skeletal muscle is not mitotically active and growth occurs only via hypertrophy. Early in life, during active growth, satellite cells contribute to muscle growth by donating myonuclei to existing myofibers [5, 6]. However, in adult muscle, satellite cells remain quiescent and only become activated in response to exercise, muscular stress or injury [5]. Satellite cells repair damaged muscle by fusing to each other or donating nuclei to existing myofibers [7, 8]. After fusion, newly attached myoblasts lose their proliferative potential and commit to terminal differentiation by elongating into muscle fibers. Chronic inactivity, type II diabetes, muscular diseases, and age result in systematic depletion of the satellite cell popula-

*Address correspondence to this author at the Biomanufacturing Research Institute and Technology Enterprise, North Carolina Central University, 1801 Fayetteville St., Durham, NC 27707, USA. Email: jsexton@nccu.edu tion, which causes decreased regenerative potential of the muscle [9-11]. Studies demonstrated that muscle growth in obese animals is significantly slower than in lean animals [12-14]. Additionally, the percentage of mitotically active satellite cells is considerably lower in obese animals than in lean animals [12-14]. Decreased satellite cell proliferative capacity largely contributes to muscle wasting diseases and makes the muscle more prone to injury which is accompanied by replacement of muscle tissue with adipose and fibrous tissues [15]. Partial loss of muscle function is associated with an increase in the number of falls and injury, loss of independence and a reduced quality of life [16].

Analysis of proliferative potential of satellite cells derived from sedentary/metabolically compromised or aged individuals serves as an appropriate model system for the drug discovery program described herein. The metabolic state and age alter the cellular environment, which greatly affects satellite cell number and mitotic activity. It has been well documented that satellite cell mitotic activity and its regenerative capacity decrease with inactivity and aging [1719]. Local environment of the cell and changes in aged cell itself, contribute to a decline in satellite cell mitotic activity in aging individuals $[15,19,20]$. Interestingly, alterations in aged cells can be reversed by (poorly characterized) circulating factors from young animals $[15,20]$. Recently published results [21] and our preliminary data are supportive of this 
hypothesis and show that there is a difference in proliferative capacity between satellite cells isolated from young and elderly human skeletal muscle biopsies. In addition to sarcopenia associated with aging, there are a number of other specific diseases that include muscle wasting as part of their pathophysiology. Some of the most common disorders associated with muscle atrophy are muscular dystrophy, chronic obstructive pulmonary disease (COPD), cachexia, end-stage renal disease and disuse atrophy [22-25]; all of which would benefit from new pharmacotherapies that improve skeletal muscle function. Overall, novel compounds that can improve or extend the health of muscle tissue will be essential to improve the quality of life in seniors and individuals that suffer from disorders that cause muscle atrophy.

Currently, there are no FDA-approved therapeutics that influence skeletal muscle maintenance or promote muscle regeneration. Targeting satellite cell proliferation with small molecule therapeutics may have a great impact on improvement of muscle metabolism and repair in diseased and nondiseased tissues alike.

Satellite cells can be easily dissociated from existing myofibers and grown in culture conditions [26] where they are able to preserve their phenotype by self-renewal [27]. Studies demonstrated that a large population of satellite cells grown in-vitro consists of quiescent satellite cells. The development of a high content in vitro cell-based model system that measures the effect of small molecules on the proliferation of human satellite cells can be used to identify pathways, biological targets and agents that mediate skeletal muscle regeneration, thereby addressing this currently unmet medical need.

Activation of satellite cells and development of muscle fiber are regulated by myogenic transcription factors including Myf5, MyoD, and myogenin. Whereas myogenin expression is associated with terminal differentiation, Myf5 and MyoD control satellite cell activation and determination of myogenic lineage [28, 29]. Antibody-based assays are often used to screen for factors that control myoblast proliferation and differentiation. However, satellite cell proliferative state or commitment to differentiation can also be assessed by detailed evaluation of cell morphology. In this study, we utilized satellite cells derived from obese adult subjects to identify molecular probes that potentiate satellite cell proliferation. We developed a high content imaging assay that can monitor satellite cell proliferation and differentiation activity, with simultaneous identification of cytotoxic compounds. In addition to the intended therapeutic endpoint, the feature-rich phenotypic data can be used to identify compounds that have other effects including the potential to induce differentiation to myotubes (myogenesis). Discovery of small molecules that can potentiate human primary satellite cell mitotic activity can provide useful insight into atrophyrelated molecular mechanisms and deliver chemical probes for treatment of muscle wasting diseases. Herein, we present a high-content/high-throughput in vitro platform for robust human primary satellite cell phenotypic evaluation to discover chemical probes with regenerative therapeutic potential. Multivariate data mining techniques were used to assess the relationship between satellite cell morphology and its proliferative state.

\section{MATERIALS AND METHODS}

\section{Satellite Cell Isolation}

All procedures involving human tissues were approved by IRB and where with the consent of adult donors. 1-2 grams of muscle tissue were obtained from rectus abdominus of obese adult female subjects with no recorded history of diabetes. Donor lot demographics were as follows: Lot-1 was composed of cells derived from one donor: 44 year-old female, BMI 36.4. Lot-2was composed of satellite cells derived from three donors: 29 year-old female, BMI 42.9; 30 year-old female, BMI 46; 29-year old female, BMI 39.3. Assay development/validation studies and pilot screening were performed on cells derived from Lot-1 and the EC50 confirmatory studies were performed on Lot- 1 and Lot- 2 to yield insight into donor-to-donor variability. The satellite cells were isolated based on the modified procedure utilized by Blau and Webster, 1981 [30]. Briefly, a sample of rectus abdominus muscle tissue was excised and transferred to Hank's Balanced Salt solution (HBSS). After removal of visible adipose and connective tissues, the muscle tissues were minced and washed in HBSS. Subsequently, the minced muscle tissue was digested in $37^{\circ} \mathrm{C}$ HBSS containing $0.2 \%$ Trypsin-EDTA, $0.1 \%$ type IV collagenase, and $1 \%$ BSA. Following tissue digestion, the isolated cells were collected by centrifugation in skeletal muscle culture media (ZenBio; DMEM, 10\% FBS, 0.05\% BSA, 0.05\% fetuin, 20 $\mathrm{ng} / \mathrm{ml} \mathrm{hEGF}, 0.4 \mu \mathrm{g} / \mathrm{ml}$ dexamethasone and antibiotics). After minimal expansion the cells were stained for desmin and shown to be $\geq 90 \%$ desmin positive; suggesting homogenous myoblast population. These preparations of myoblasts were also $\geq 85 \% \mathrm{CD} 56+$. The satellite cells were expanded (passage 4) and cryogenically preserved in skeletal muscle media supplemented with 5\%DMSO.

\section{Assay Validation with ALK5 Inhibitor}

Active in receptor-like kinase 5 (Alk5) inhibitor (LY364947) was utilized as a positive control in the present cellular proliferation assay. It has been demonstrated that signaling via the TGF- $\beta$ pathway results in the reduction in proliferation and healing of skeletal muscle [31]. ALK5, also known as TGF- $\beta$ R1, is a receptor for TGF- $\beta$, and small molecule inhibitors have been developed that inhibit kinase activity associated with Alk5 [32]. Treatment of cells with the Alk-5 inhibitor, LY364947 (1 uM), significantly reduced the doubling times of satellite cells from both young and, to a greater extent, old donors (data not shown). These preliminary data confirm the ability of the assay to serve as a relevant phenotypic drug discovery platform to discover agents that can modulate proliferative capacity of skeletal muscle satellite cells.

To establish the optimal concentration of LY364947 as the positive control, satellite cells from Lot-1 were screened in a 7-point, 2-fold dilution series between $100-0.5 \mu \mathrm{M}$ of LY364947 with 48 replicates per condition. Detailed cell plating conditions are described in Satellite Cell Proliferation Assay section. Based on the analysis of assay window and replicate variability, it was determined that $25 \mu \mathrm{M}$ of LY364947 results in maximum proliferation rate in satellite cells derived from obese subjects and was selected as the positive control concentration. 


\section{Compound Libraries}

Two commercially available compound libraries consisting of 1120 FDA-approved drugs (Prestwick Chemical Library ${ }^{\circledR)}$ and 502 purified natural products (Enzo Life Sciences) were screened on satellite cells derived from obese female donors. The compound plates were stored in deepwell polypropylene blocks, at $4{ }^{\circ} \mathrm{C}$ with no humidity control. All compounds were resuspended in $100 \%$ DMSO. The compound libraries were plated in Axygen384-well rigid PCR plates (Cat no321-67-051) at 1000X concentration for both single-concentration screening and dose-response confirmation.

\section{Satellite Cell Proliferation Assay}

Satellite cells were thawed and plated directly from cryopreservation and diluted to the final concentration of $0.075 \times 10^{6}$ viable cells $/ \mathrm{ml}$. The satellite cells were then plated in 384 well collagen-coated flat bottom imaging plates (Greiner Cell Coat Clear Cat-No:781956). 30uL of prewarmed growth media was added to each well, followed by $20 \mu 1$ of cells (total 1500 cells/well). Cells were observed to attach at approximately four hours post plating and compounds were added shortly thereafter. Cells were allowed to incubate with compounds for $72 \mathrm{hrs}$ in humidified $37^{\circ} \mathrm{C}, 5 \%$ $\mathrm{CO}_{2}$ incubator.

In the pilot screen, compounds were applied to Lot-1 satellite cells with the Biomek NX workstation (BeckmanCoulter, Brea, CA) equipped with a $50 \mathrm{~nL}$ pin tool array (V\&P Scientific, San Diego, CA) for a direct 1000-fold dilution, thereby avoiding an intermediate dilution step. The final concentration of compounds derived from Prestwick library was $1 \mu \mathrm{M}$ and the final concentration of compounds derived from Natural Product library was $5 \mu \mathrm{M}$. Controls were added using the pin tool array in a separate plate where columns 1-2 and 23-24 were negative (DMSO) and positive (25 $\mu \mathrm{M}$ of LY364947) controls, respectively. Plate-based normalization was performed using the mean of controls, yielding activity scores between $0-100 \%$ (Fig. 3). Compounds with $40 \%$ proliferative activity or above (approximately $\mu+3 \sigma$ ) were selected for dose response analysis.

Compounds selected from the pilot screen were serially diluted in a 10-point/2-fold format for an EC50 doseresponse confirmation derived from Lot-1 and Lot-2 (mixed donor lot). The serial dilution of compounds was performed in Axygen conical 384-well PCR plates. A Biomek ${ }^{\circledR} 3000$ was utilized to perform a 10-point 2-fold serial dilution series. Serially diluted compounds were applied to the cell plate by four subsequent pin tool transfers, which resulted in Natural Product concentrations ranging from $20 \mu \mathrm{M}$ to 0.039 $\mu \mathrm{M}$ and Prestwick concentrations ranging from $4 \mu \mathrm{M}$ to $0.0078 \mu \mathrm{M}$. As in the pilot screen, the controls were in columns 1-2 (DMSO) and 23-24 (25 $\mu \mathrm{M}$ of LY364947). The dose response compounds were tested in intra-plate triplicates and the EC50 values were calculated based on the average of each concentration.

\section{Cell Plate Fix/Stain Procedure}

Following the 72-hr incubation period, media was removed with Biomek NX workstation. Subsequently $30 \mu \mathrm{L}$ of IX PBS (pH 7.4) containing fresh $4 \%$ Formaldehyde and 10 $\mu \mathrm{g} / \mathrm{mL}$ Hoechst-33342 was added to the cells and then incubated for $30 \mathrm{~min}$ at $37^{\circ} \mathrm{C}$. $30 \mu \mathrm{L}$ of stain and fixativecontaining PBS was aspirated out and replaced with $40 \mu \mathrm{L}$ of PBS. All the liquid additions were performed at the slowest Biomek NX dispense speed to prevent cell detachment. Following PBS addition, plates were sealed with ThermoABgene plate sealer and imaged on BD Pathway 855 bioimager (Becton Dickenson, San Jose CA).

\section{High Content Screening Assay: Cell Counts and Pheno- typic Analysis}

Two passes of image acquisition were performed using a BD Pathway 855 with either an Olympus UPlanSApo4X (entire-well cell counting) or an Olympus UPlanSApo10X (cell morphology) objective lens. To assure an ideal signal-to noise ratio, the exposure times and laser-based autofocus were adjusted for each plate prior to image collection using the BD Attovision software. A 2 X2 montage image was acquired for each well of 384-well plate at 4X magnification. The 2X2 montage image area at $4 \mathrm{X}$ magnification assured an entire well coverage.

We found that satellite cell morphology was easily distinguishable with either Hoechst-33342 alone or multiplexed with Cell Tracker Red CMTPX. Therefore, we selected Hoechst-33342 alone to visualize both nuclei and cytoplasm. To establish compound-related changes in cellular phenotype, satellite cells were imaged with $10 \mathrm{X}$ objective lens. The 10X magnification was found to be ideal to visualize changes in cell shape parameters.

\section{Cell Quantification and Quantitation of Cellular Pheno- type}

\section{Image Processing}

Cell Profiler software was used for cellular segmentation/detection and to assess changes in cellular morphology [33]. Since satellite cells have substantial nucleic acid content in the cytoplasm, the Hoechst-33342 image was used to identify both nuclei and cytoplasm using a two-pass thresholding technique [34]. In brief; an image-processing pipeline was developed to 1) automatically identify nuclei within illumination-corrected Hoechst-33342 image using a high (5.0) threshold correction factor, 2) mask cytoplasm by dilating the nuclear mask out to the edge of the Hoechst-33342 cytoplasmic intensity using a lower threshold correction factor (1.5), and 3) measurement of Hoechst intensity inside both nuclear and cytoplasmic masks, and 4) measurement of nuclear and cytoplasmic size/shape parameters. Hundreds of phenotypic features were extracted for each observed cell and were recorded in an SQL database for data analysis/mining.

Both well-level and cell-level data were analyzed using JMP9 (SAS software, Cary NC) and Excel pivot tables and were merged with compound treatment information using Screen Able high-throughput screening software (Screen Able Solutions, Chapel Hill NC).

\section{Statistical Analysis}

Typical output from cell segmentation and feature extraction yields between 50-200 primary features per cell based on intensity measurements, morphological characteristics, 

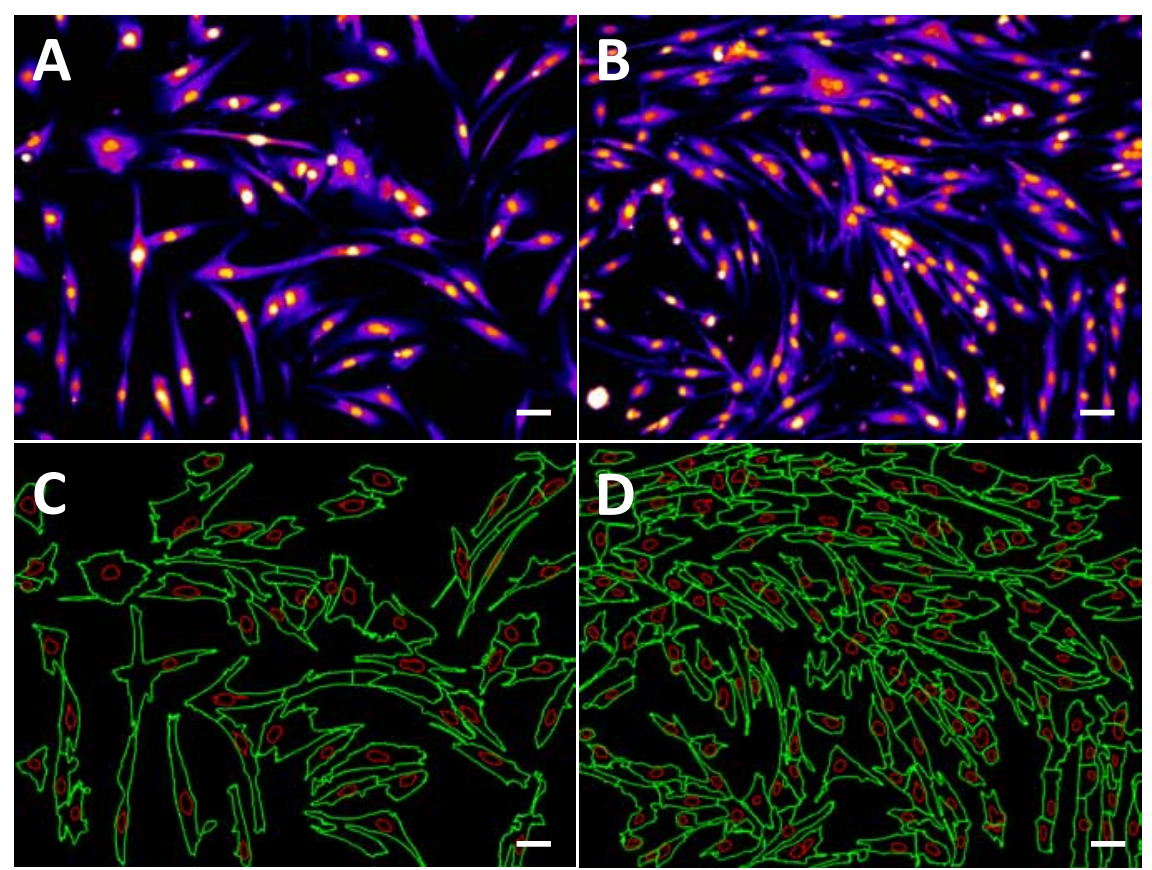

E

\begin{tabular}{|c|c|c|c|c|c|c|c|}
\hline Treatment & Donor & Cell Count & Perimeter & $\begin{array}{c}\text { Major Axis } \\
\text { Length }\end{array}$ & Area & Eccentricity & $\begin{array}{c}\text { Form } \\
\text { Factor }\end{array}$ \\
\hline DMSO & 1 & 86.72 & 789.40 & 156.47 & 5070.77 & 0.86 & 0.12 \\
\hline & 2 & 65.76 & 939.66 & 164.18 & 6302.61 & 0.85 & 0.11 \\
\hline LY364947 & 1 & 105.02 & 706.32 & 141.73 & 4468.71 & 0.84 & 0.13 \\
\hline & 2 & 103.86 & 769.56 & 147.19 & 5293.52 & 0.84 & 0.13 \\
\hline
\end{tabular}

Fig. (1). Comparison of Lot 1 (A-D) satellite cells treated for 72 hrs with $0.1 \%$ DMSO (negative control: A,C) and with $25 \mu \mathrm{M}$ LY364947 (positive control: B,D). Cells were seeded at 1500 cells/well. Images portray satellite cells stained with Hoechst 33342 (A, B) and corresponding two phase detection showing nuclei (red) and cytoplasmic outline (green) (C, D). Images are at 100X magnification, scale bar $=50 \mu \mathrm{m}$. (E) Quantification of cellular parameters that were most distinct between negative and positive controls. Cellular dimension values are expressed in pixels (pixel size $=0.61 \mu \mathrm{M}$ ).

and subcellular features that can be aggregated as a "phenotypic fingerprint". Multivariate statistical techniques like principal component analysis, partial least squares regression and clustering were used for exploratory data analysis. The ultimate goal was data reduction towards a single robust scoring system that captures the intended response and is tolerant to outlier effects. In early assay development, we evaluated proliferation vs. differentiation-dependent changes in cellular phenotype.

The effect of test compounds was scored using multivariate scoring system to detect true biological effects, allowing for discrete analysis of potentially important sub-population effects. Screen Able high-throughput screening software was utilized for merging biological data and chemical structure. The screening data management system has proven to produce valid primary and secondary screening results for numerous HTS and HCS assays yielding a $96.4 \%$ replication rate and a $13 \% \mathrm{CV}$ in EC50 determination (data not shown). Pilot screening data was assessed per-plate for robustness (Z-prime above 0.35 ) and hits were chosen using a three-standard deviation cutoff from the mean on cell count per well.

\section{Dose Response Model}

With the goal of detecting compounds that are doseresponsive for increased proliferation in a cell-based assay, there are two distinct effect regimes; 1) at lower doses the compounds are stimulatory and 2) at higher concentrations, proliferation effects reverse as the small molecule toxicity effects manifest. Compounds with a larger separation between onsets of efficacy vs. toxicity can be prioritized as an initial indication of therapeutic index. To capture these two distinct regimes, a bell-shaped dose-response model was used to capture both the onset/plateau of the therapeutic effect and the onset of toxicity. The innate toxicity profile gained through bioimaging/high-content screening of compounds is invaluable and can be used for early triage of scaffolds to help reduce the overall attrition rates for in vivo studies.

\section{RESULTS}

\section{Optimization of Positive Control Concentration Assay Parameters}

Based on the high-replication dose response analysis in our initial positive control screen run, we established that 25 $\mu \mathrm{M}$ of LY364947 results in a maximum proliferation rate in satellite cells derived from both donor lots (Fig. 1 and 2). Over 72-hrs, LY364947 increased cell count by $17 \%$ in a single donor lot (Lot-1) and by $37 \%$ in a mixed donor lot (Lot-2). Next, plating density was optimized with respect to 


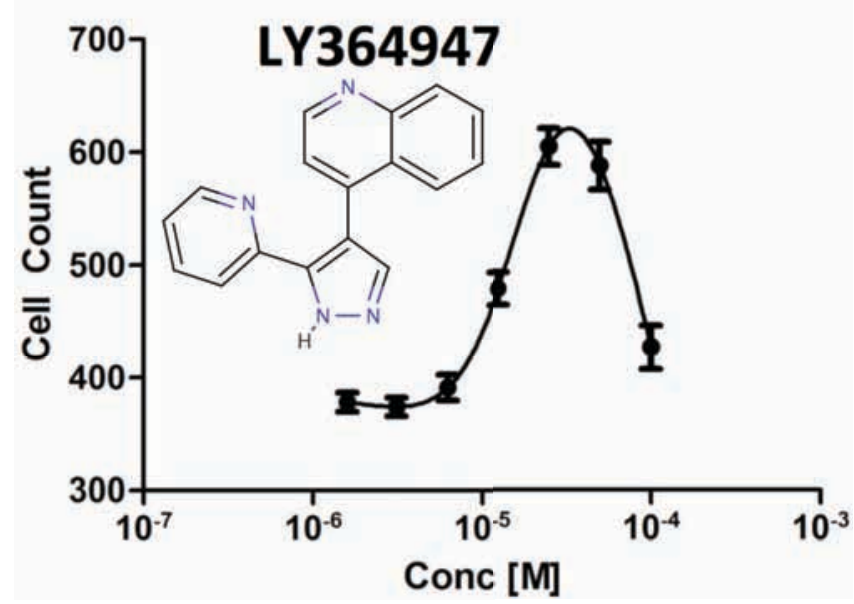

Fig. (2). Dose response curve for the positive control compound, LY364947(Lot 2).

the assay window (cell count of negative control/DMSO vehicle vs. $25 \mu \mathrm{M}$ of LY364947). Our initial assumption was that by plating fewer cells-per-well, we would achieve a wider assay window given the same amount of proliferation time without approaching contact inhibition. After examining 1000, 1500, and 2000 cells per well, we determined that 1500 cells per well provided the most robust assay window. After careful examination of the cellular phenotype, we realized that by plating more cells, they were up against a natural differentiation/proliferation checkpoint. However, in untreated wells, proliferation was rapidly declining due to contact stimulated differentiation and elongation of cells into myotubes. With the addition of LY364947, the cells were able to push past the differentiation checkpoint and continue proliferating, resulting in higher cell counts and smaller cells, which is indicative of stimulating satellite cell proliferation. In addition to increased cell counts, the LY364947 had an effect on factors that define cellular phenotype such as cell perimeter, major axis length, cell area, eccentricity, and form factor (Fig. 1). Strong correlation between cell number and cell size is indicative of compounds that in- crease satellite cell proliferation and, at the same time, delay differentiation.

\section{Screening Assay for Stimulation of Proliferation}

After conducting a pilot screen of Prestwick and Natural product libraries, we were able to identify and cluster compounds into discrete categories based on toxicity, proliferative capacity, potential myogenic properties and intermediate activity (Fig. 3, 4). In this pilot screen, we were liberal in selecting potential hits for compound validation, since we only screened a limited number of compounds. The main aim for the pilot screen was to identify compounds that cause a significant increase in satellite cell proliferation. The singleconcentration pilot screen of Lot- 1 cells with Prestwick and Natural Product libraries resulted in 22 compounds with $40 \%$ or higher activity above the negative control mean (Fig. 3).

The selected compounds were screened in triplicate dose/response for both donor lots. In Lot-1, 15 out of 22 compounds were dose responsive ( $68 \%$ confirmation rate). However, only two compounds were found to be dose responsive in Lot-2 (Geraldol and Bromopride, Fig. 5). Geraldol originated from the Natural Product library and Bromopride originated from the Prestwick library. The calculated EC50 values for Geraldol and Bromopride were $0.65 \mu \mathrm{M}$ and $0.66 \mu \mathrm{M}$, respectively and were nearly identical in both lots. Since donor to donor variability in satellite cell proliferation is often observed in response to compound treatment, the goal was to identify compounds that significantly increased satellite cell proliferation rate in both donor lots. Additionally, the aim was to find compounds that cause increases in satellite cell proliferation in the highest number of donors despite donor to donor variability. Using lots composed of cells derived from multiple donors (such as our Lot-2), helps to ensure that compounds selected are effective on multiple donors.

\section{Assessment of Cellular Phenotype}

There are key morphological features that indicatechanges in the proliferative state of satellite cells. Principal

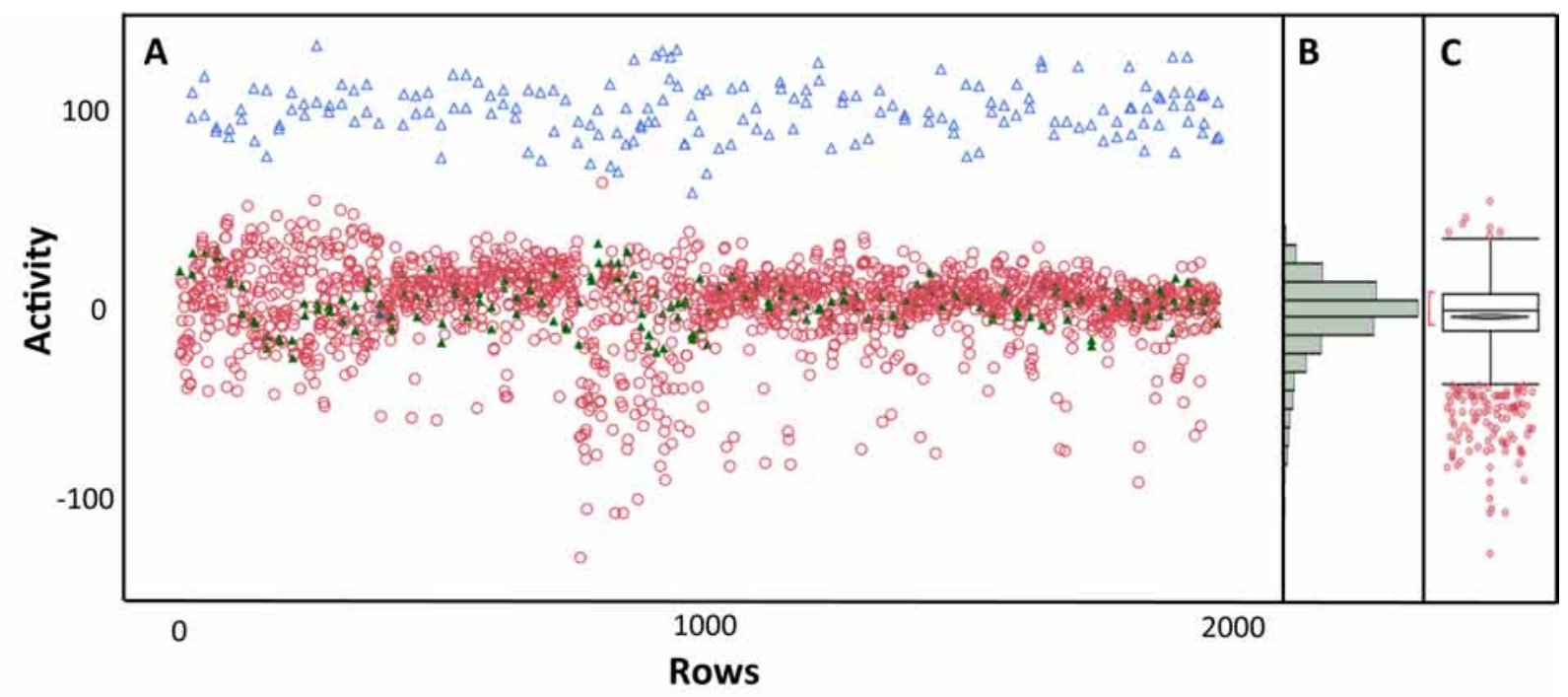

Fig. (3). High content screening data for satellite cell proliferators. (A) Scatterplot for 1600 test compounds screened (red circles), positive control (LY364947, blue triangles), and negative control (DMSO, green-filled triangles); (B) histogram portraying normal statistical distribution; (C) box plot showing distribution statistics and outlier compounds. 


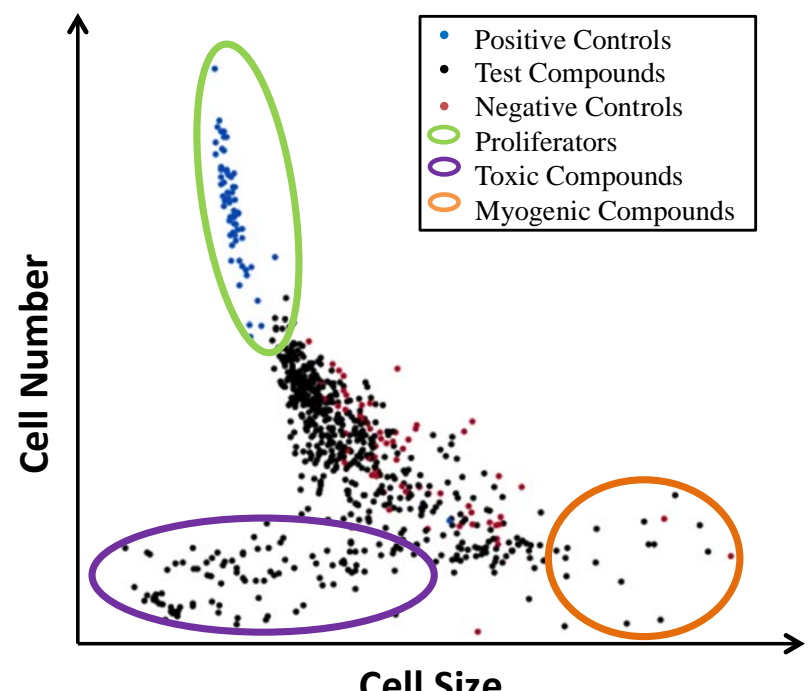

Fig. (4). Screening dot-plot showing the relationship between cell size and satellite cell proliferation.

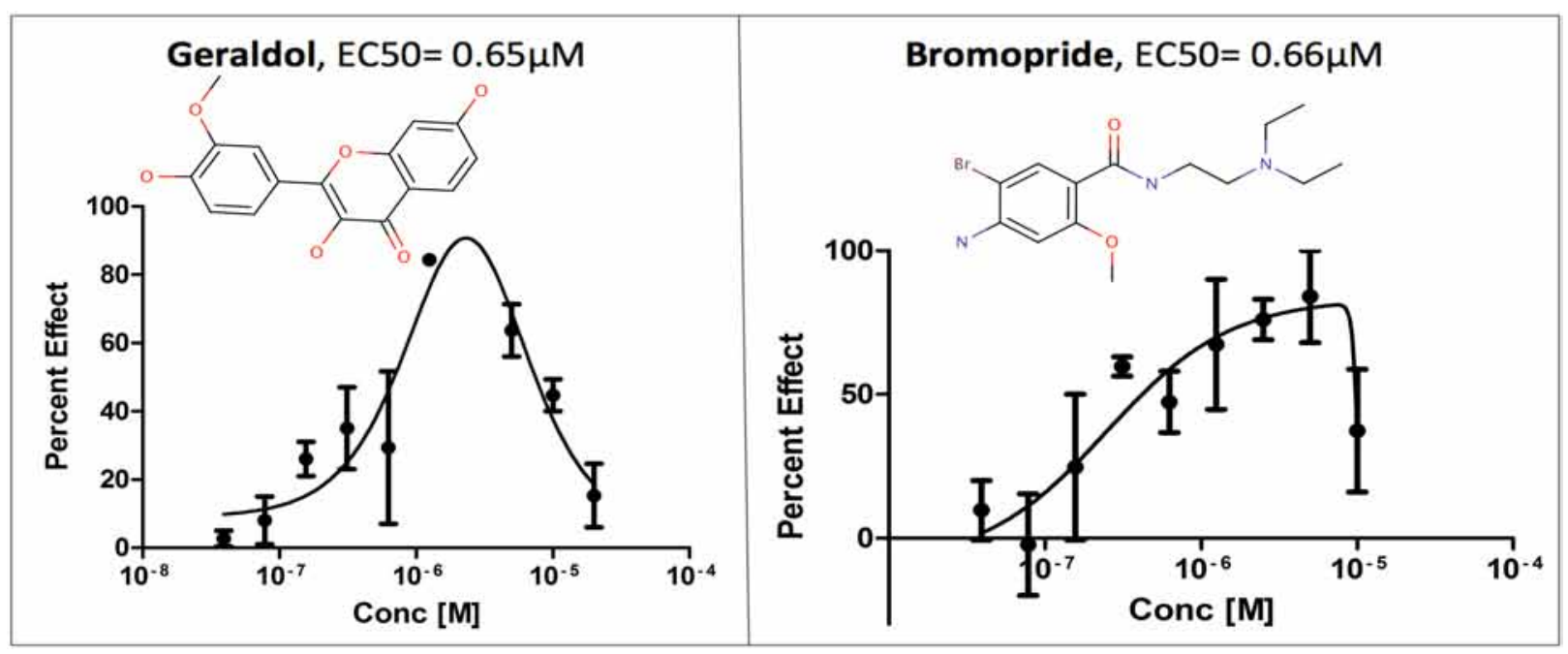

Fig. (5). Log-transformed dose response curves for two compounds that significantly increased proliferation rate in satellite cells (Lot 2).

Component Analysis (PCA) of approximately 100 different cellular output parameters resulted in 6 factors that correlated best with the positive control treatment (Fig. 1E). These parameters allow for identification of distinct modes of action of analyzed compounds through natural clustering (Fig. 4). Parameters including small satellite cell cytoplasmic area, small cellular length and perimeter, decreased eccentricity, and increased form factor all indicate increased proliferation. After screening two highly-annotated small molecule libraries, we were able to detect different modes of action through visualization of key phenotypic parameters discovered in the PCA analysis across the compounds screened. We observed natural clustering of compound effects and were able to identify common modalities/cell fates. For example, one cluster of compounds resulted in large cytoplasmic area, increased cellular length and perimeter, increased eccentricity and decreased form factor, all signaling that satellite cells are differentiating into myotubes and are entering the process of myogenesis. Once satellite cells enter myogenesis, they terminally differentiate, stop proliferating and begin to fuse and form long chains of nuclei. From our pilot screen performed on Lot-1, we identified a number of compounds that may have a myogenic potential including: Pratol, Limonin, and Idirubin. The activity of these compounds will be confirmed by EC50 studies in multiple donor lots in future studies.

The pilot screen also revealed a large number of compounds that cause satellite cell toxicity. Some of the most toxic compounds identified were: Camptothecin, Parthenolide, and Cantharidin. Because these compounds were screened at a single concentration, it is unknown if these compounds have activity at lower concentrations.

\section{DISCUSSION}

\section{Satellite Cells and Muscle Health}

Satellite cells are indispensable to the recovery and maintenance of skeletal muscle. Under normal physiological conditions, satellite cells contribute to muscle growth and repair 
by proliferating and donating nuclei to pre-existing myofibers. Because satellite cells function as adult muscle stem cells, they are able to restock their own population via a process of self-renewal [27]. Cultured satellite cells encompass many phenotypic characteristics of quiescent satellite cells present in in vivo systems and therefore present a great model for studying satellite cell stimulation, renewal, and proliferation $[28,35]$.

Despite their ability to self-renew, satellite cell proliferative and regenerative capacity can be altered by many physiological and environmental stressors. Inactivityassociated muscle disuse, metabolic disorders, physical trauma, denervation, muscle wasting diseases, and sarcopenia have detrimental effects on satellite cell population and function. During mild injury or mild loss of muscle function, satellite cells migrate to the site of injury and begin the process of repair. As a result of severe physical myotrama, basal lamina may break apart and satellite cells begin to migrate to neighboring myofibers instead of the site of the injury, and the repair process does not proceed [36]. Prolonged decrease in muscle activity caused by factors such as muscle unloading, malnutrition, obesity and denervation results in significant reduction in myonuclear number and muscle atrophy [37-39]. Progressive decrease in satellite cell reserve/quiescent population results in myonuclear apoptosis and in decreased input of growth factors, such as IGF-1, which stimulate satellite cell proliferation. Additionally, satellite cell proliferative potential in atrophic muscle is reduced by replacement of muscle tissue with fibrotic tissue and confinement of satellite cells within endomysial tubes [39].

The physical age of an individual also plays an important role in satellite cells' ability to self-renew and proliferate. Satellite cell-stimulated skeletal muscle repair process gradually decreases with age $[10,11,17]$. Along with a decrease in satellite cell mitotic activity, the satellite cell quiescent population also decreases with age. These changes are major reasons for the development of sarcopenia and decreased quality of life in the elderly. Therefore, discovery of small molecule therapeutics that aid in increasing satellite cell number is crucial in preventing and possibly treating muscle atrophy in aging individuals.

In the current study, we utilized satellite cell cultures derived from obese human subjects. Obesity-related inactivity and resulting metabolic imbalance cause phenotypic alterations in skeletal muscle. Obesity leads to reduced satellite cell proliferative capacity [12] and significant decrease in fast-twitch myofiber size [14]. Furthermore, obese subjects suffering from Type II Diabetes have higher ratio of insulinresistant muscle fibers, which are more prone to oxidative damage and atrophy [9, 13, 40-42]. Consequently, our in vitro satellite cell platform offers an excellent model for studying potential satellite cell proliferators in metabolically compromised individuals and presents promise for treatment of atrophic muscles affected by serious diseases such as Type II Diabetes

\section{Determining Satellite Cell Fate}

Depending on the environmental and metabolic cues, satellite cells either remain quiescent, proliferate, or enter myogenesis. In our pilot screen, we were able to identify compounds that induce satellite cell proliferation, stimulate myoblast differentiation, or cause cellular death. Compounds that induced proliferation in the pilot screen play many different biochemical roles that can possibly be tied to increased satellite cell activity. A number of positive hits from this study have hypotensive activities (from literature searching from highly annotated compounds), increase activity of intercellular insulin, and mimic caloric restriction. Recent research demonstrated that drugs lowering blood pressure may be beneficial in treatments of muscular dystrophy [43]. Furthermore, many studies show that insulin signaling and caloric restriction stimulate satellite cell mitotic activity [9, 18, 44-49]. In future studies we will extend screening efforts to larger small molecule libraries and confirm our primary compound hits on satellite cells derived from a variety of new human donor lots with muscular atrophies caused by aging and disease.

Our dose response study confirmed two compounds (Geraldol and Bromopride) to be active in single donor satellite cell lot and triple donor satellite cell lot. Geraldol(3,4',7trihydroxy-3'-methoxyflavone) is a metabolite of fisetin [50], a flavonoid that mimics calorie restriction process [51]. Geraldol has shown activity in three confirmatory potency bioassays for inhibitors of human lipoxygenase, hydroxysteroid dehydrogenase, and Caspase-1 (PubchemAID: 887, 893, 923). Bromopride (4-amino-5-bromo-N-[2-(diethylamino)ethyl]-2-methoxybenzamide) has been shown to function as a dopamine-antagonist and anti-emetic [52, 53]. Bromopride was active in one confirmatory assay for P45cyp1a2 activators (Pubchem AID: 410), and in one potency assay for antagonists of the human M1 muscarinic receptor (Pubchem AID: 602250). Further studies are necessary to determine the exact mechanism by which Geraldol and Bromopride stimulate satellite cell mitotic activity.

The single point pilot screen resulted in a number of compounds that induced myogenesis. The compounds that significantly increased cellular size and halted proliferation were Pratol, Limonin, and Idirubin. The activity of these compounds still needs to be confirmed by EC50 studies in multiple donors. Data on these compounds is very limited and further experiments may be needed to confirm their myogenetic function.

The pilot screen also revealed a large number of compounds that caused satellite cell toxicity. Some of the most toxic compounds identified were: Camptothecin, Parthenolide, and Cantharidin. Camptothecin is an anti-tumor agent that inhibits the DNA topoisomerase I $[54,55]$. Parthenolide also has anti-cancer properties. It has been shown to induce apoptosis in acute myelogenous leukemia cells [56]. Cantharidinis a toxic agent that causes burns and blisters [57]. Because of the truly toxic biological nature of these compounds, it is likely that even lower concentrations will cause satellite cell death.

\section{Donor to Donor Variability}

The pilot screen resulted with 22 compounds that had high proliferative activity (at least $40 \%$ above negative control) in a single donor lot. Out of 22 selected compounds, 15 were dose responsive in a single donor lot and 2 had con- 
firmed activity in a satellite cell lot that was composed of three donors. Although the satellite cells were derived from subjects with very similar demographics, we still observed large donor-to-donor variability in response to the positive control compound and in response to test compounds. Satellite cells readily change their proliferative capacity in response to many physiological and environmental factors [58]. Consequently, sample selection based on donor sex, age, tobacco use, presence of diabetes, or BMI may not provide an adequate assessment of the proliferative state of muscle satellite cells. Since the BMI does not provide an accurate measure of a total body fat, evaluating lean to fat ratio of an individual prior to sample acquisition may decrease donor to donor variability in response to tested compounds. However, we have determined it necessary to adjust assay timing (compound exposure period) to reflect substantial differences in satellite cell doubling time observed in donors with similar demographics. Normalizing the compound exposure period to a static number of cell doublings will provide the most robust and unbiased analysis of proliferative potential across widely variable donor lots. Additionally, we observed that optimal positive control concentration for one donor results in cell toxicity in another donor. Therefore, it is necessary to perform dose response analysis of the positive control for each cell lot to determine the positive control concentration that will result in maximum activity.

\section{Future Studies}

While high content screening/image cytometry provides a very accurate method for counting cells and observing cellular phenotype, additional confirmatory experiments are necessary to verify changes in cell proliferation status. We will perform pulse-chase EdU incorporation secondary/orthogonal assays to directly measure the percent of the population in S-phase in the treatment group relative to negative control (DMSO vehicle) using the Click-iT® EdU cell proliferation kit (Life Technologies, Carlsbad, CA). Mitotic activity will be assessed in this assay using either imaging or flow cytometry with similar performance. Future studies can be optimized by determining the exact point of proliferation activation and may shorten the time required for compound treatment. Follow up studies will involve in vivo treatment with selected compounds utilizing atrophic/or dystrophic and healthy mice models, and subsequent estimation of muscle satellite cell proliferative status by EdU profiling.

The novel high content, high throughput skeletal muscle satellite cell platform developed herein was validated for assay performance through screening of 1600 highlyannotated compounds. These data are highly suggestive that this platform can be readily adapted to a significantly larger screening effort (>100,000 compounds). In the present study we developed a screening assay for satellite cells derived from obese adult female subjects. Because obesity often results in inactivity and significant changes in cellular metabolism, satellite cells derived from obese individuals present a very good model for studying muscular atrophy. The current screening system will be utilized in experiments involving satellite cells derived from elderly individuals and individuals suffering from muscle wasting diseases. Our robust high content phenotypic assay provides a fast and effective screen for compounds that will have wide applications in muscle research and will be beneficial in the treatment of muscular disorders.

\section{ACKNOWLEDGEMENTS}

This work was supported in part by a grant from the NIH/NIAMS AR058026 (BC).

\section{REFERENCES}

[1] Bauer JM, Wirth R, Volkert D, Werner H, Sieber CC. Malnutrition, sarcopenia and cachexia in the elderly: from pathophysiology to treatment - conclusions of an international meeting of experts, sponsored by the BANSS Foundation. Deutsche Medizinische Wochenschrift 2008; 133(7): 305-10.

[2] Morley JE, Thomas DR, Wilson MMG. Cachexia: pathophysiology and clinical relevance. Am J Clin Nutr 2006; 83(4): 735-43.

[3] Mauro A. Satellite cell of skeletal muscle fibers. J Biophys Biochem Cytol 1961; 9(2): 493-7.

[4] Montarras D, Morgan J, Collins C, et al. Direct isolation of satellite cells for skeletal muscle regeneration. Science 2005; 309(5743): 2064-7.

[5] Mozdziak PE, Schultz E, Cassens RG. Myonuclear accretion is a major determinant of avian skeletal muscle growth. Am J PhysiolCell Physiol 1997; 272(2): C565-C71.

[6] Moss FP, Leblond CP. Satellite cels as a source of nuclein in muscles of growing rats. Anatomical Rec 1971; 170(4): 421-7.

[7] Moss FP, Leblond CP. Nature of didving nuclein in skeletal muscle of growing rats. J Cell Bio 1970; 44(2): 459-61.

[8] Hawke TJ, Garry DJ. Myogenic satellite cells: physiology to molecular biology. J Appl Physiol 2001; 91(2): 534-51.

[9] Aguiari P, Leo S, Zavan B, et al. High glucose induces adipogenic differentiation of muscle-derived stem cells. Proc Natl Acad Sci USA 2008; 105(4): 1226-31.

[10] Allbrook DB, Han MF, Hellmuth AE. Population of muscle satellite cells in relation to age and mitotic activity. Pathology 1971; 3(3): 233-43.

[11] Mozdziak PE, Schultz E, Cassens RG. Satellite cell mitotic activity in posthatch turkey skeletal muscle growth. Poult Sci 1994; 73(4): 547-55.

[12] Purchas RW, Romsos DR, Allen RE, Merkel RA. Muscle growth and satellite cell proliferative activity in obese (ob/ob) mice. J Anim Sci 1985; 60(3): 644-51.

[13] Sishi B, Loos B, Ellis B, Smith W, du Toit EF, Engelbrecht A-M. Diet-induced obesity alters signalling pathways and induces atrophy and apoptosis in skeletal muscle in a prediabetic rat model. Exp Physiol 2011; 96(2): 179-93.

[14] Kemp JG, Blazev R, Stephenson DG, Stephenson GMM. Morphological and biochemical alterations of skeletal muscles from the genetically obese (ob/ob) mouse. Int J Obes 2009; 33(8): 831-41.

[15] Brack AS, Conboy MJ, Roy S, et al. Increased Wnt signaling during aging alters muscle stem cell fate and increases fibrosis. Science 2007; 317(5839): 807-10.

[16] Rantanen T, Sakari-Rantala R, Heikkinen E. Muscle strength before and mortality after a bone fracture in older people. Scand $\mathrm{J}$ Med Sci Sports 2002; 12(5): 296-300.

[17] Gibson MC, Schultz E. Age-related differences in absolute numbers of skeletal muscle satellite cells. Muscle Nerve 1983; 6(8): 574-80.

[18] Nierobisz LS, Felts V, Mozdziak PE. The effect of early dietary amino acid levels on muscle satellite cell dynamics in turkeys. Comp Biochem Phys B 2007; 148(3): 286-94.

[19] Brack AS, Rando TA. Intrinsic changes and extrinsic influences of myogenic stem cell function during aging. Stem Cell Rev 2007; 3(3): 226-37

[20] Conboy IM, Conboy MJ, Wagers AJ, Girma ER, Weissman IL, Rando TA. Rejuvenation of aged progenitor cells by exposure to a young systemic environment. Nature 2005; 433(7027): 760-4.

[21] Corbu A, Scaramozza A, Badiali-DeGiorgi L, et al. Satellite cell characterization from aging human muscle. Neurol Res 2010; 32(1): 63-72.

[22] Inui A. Cancer anorexia-cachexia syndrome: Current issues in research and management. CA-Cancer J Clin 2002; 52(2): 72-91. 
[23] Mitch WE, Bailey JL, Wang X, Jurkovitz C, Newby D, Price SR. Evaluation of signals activating ubiquitin-proteasome proteolysis in a model of muscle wasting. Am J Physiol Cell Physiol 1999; 276(5): C1132-C8.

[24] McKinnell IW, Rudnicki MA. Molecular mechanisms of muscle atrophy. Cell 2004; 119(7): 907-10.

[25] Reid MB, Li YP. Tumor necrosis factor-alpha and muscle wasting: a cellular perspective. Respir Res 2001; 2(5): 269-72.

[26] Blau HM, Brazelton TR, Weimann JM. The evolving concept of a stem cell: Entity or function? Cell 2001; 105(7): 829-41.

[27] Collins CA, Partridge TA. Self-renewal of the adult skeletal muscle satellite cell. Cell Cycle 2005; 4(10): 1338-41.

[28] Zammit PS, Golding JP, Nagata Y, Hudon V, Partridge TA, Beauchamp JR. Muscle satellite cells adopt divergent fates: a mechanism for self-renewal? J Cell Bio 2004; 166(3): 347-57.

[29] Collins CA, Olsen I, Zammit PS, et al. Stem cell function, selfrenewal, and behavioral heterogeneity of cells from the adult muscle satellite cell niche. Cell 2005; 122(2): 289-301.

[30] Blau HM, Webster C. Isolation and characterization of human muscle cells. Proc Natl Acad Sci USA 1981; 78(9): 5623-7.

[31] Carlson ME, Conboy MJ, Hsu M, et al. Relative roles of TGF-beta 1 and $\mathrm{Wnt}$ in the systemic regulation and aging of satellite cell responses. Aging Cell 2009; 8(6): 676-89.

[32] Gellibert FO, Woolven J, Fouchet MH, et al. Identification of 1,5naphthyridine derivatives as a novel series of potent and selective TGF-beta type I receptor inhibitors. J Med Chem 2004; 47(18): 4494-506.

[33] Carpenter AE, Jones TR, Lamprecht MR, et al. CellProfiler: image analysis software for identifying and quantifying cell phenotypes. Genome Biol 2006; 7(10): 31.

[34] Sexton JZ, Williams KP. Evaluating the Peroxisomal Phenotype in High-Content Toxicity Profiling. In: Steinberg P, Ed. HighThroughput Screening Methods in Toxicity Testing: Wiley 2013.

[35] Yablonka-Reuveni Z, Anderson JE. Satellite cells from dystrophic $(\mathrm{mdx})$ mice display accelerated differentiation in primary cultures and in isolated myofibers. Dev Dyn 2006; 235(1): 203-12.

[36] Schultz E, McCormick KM. Skeletal muscle satellite cells. Rev Physiol, Biochem Pharmacol 1994; 123: 213-57.

[37] Carlson BM, Faulkner JA. Reinnervation of long term denervated rat muscle freely grafted into an innervated limb. Exp Neurol 1988; 102(1): 50-6.

[38] Dedkov EI, Kostrominova TY, Borisov AB, Carlson BM. Reparative myogenesis in long-term denervated skeletal muscles of adult rats results in a reduction of the satellite cell population. Anatomical Rec 2001; 263(2): 139-54.

[39] Borisov AB, Dedkov EI, Carlson BM. Differentiation of activated satellite cells in denervated muscle following single fusions in situ and in cell culture. Histochem Cell Biol 2005; 124(1): 13-23.

[40] Schuler M, Ali F, Chambon C, et al. PGC1 $\alpha$ expression is controlled in skeletal muscles by PPAR $\beta$, whose ablation results in fiber-type switching, obesity, and type 2 diabetes. Cell Metabol 2006; 4(5): 407-14.

[41] Nyholm B, Qu ZQ, Kaal A, et al. Evidence of an increased number of type IIb muscle fibers in insulin-resistant first-degree relatives of patients with NIDDM. Diabetes 1997; 46(11): 1822-8.

[42] Costford SR, Crawford SA, Dent R, McPherson R, Harper ME. Increased susceptibility to oxidative damage in post-diabetic human myotubes. Diabetologia 2009; 52(11): 2405-15.
[43] D'Angelo MG, Gandossini S, Boneschi FM, et al. Nitric oxide donor and non steroidal anti inflammatory drugs as a therapy for muscular dystrophies: Evidence from a safety study with pilot efficacy measures in adult dystrophic patients. Pharmacol Res 2012; 65(4): 472-9.

[44] Haddad F, Adams GR. Exercise effects on muscle insulin signaling and action - Selected contribution: Acute cellular and molecular responses to resistance exercise. J Appl Physiol 2002; 93(1): 394403.

[45] Hill M, Goldspink G. Expression and splicing of the insulin-like growth factor gene in rodent muscle is associated with muscle satellite (stem) cell activation following local tissue damage. J Physiol Lond 2003; 549(2): 409-18.

[46] Adamo ML, Farrar RP. Resistance training, and IGF involvement in the maintenance of muscle mass during the aging process. Ageing Res Rev 2006; 5(3): 310-31.

[47] Gaster M, Petersen I, Hojlund K, Poulsen P, Beck-Nielsen H. The diabetic phenotype is conserved in myotubes established from diabetic subjects - Evidence for primary defects in glucose transport and glycogen synthase activity. Diabetes 2002; 51(4): 921-7.

[48] Guillet-Deniau I, Pichard AL, Kone A, et al. Glucose induces de novo lipogenesis in rat muscle satellite cells through a sterolregulatory-element-binding-protein-1c-dependent pathway. J Cell Sci 2004; 117(10): 1937-44.

[49] Lee S, Barton ER, Sweeney HL, Farrar RP. Viral expression of insulin-like growth factor-I enhances muscle hypertrophy in resistance-trained rats. J Appl Physiol 2004; 96(3): 1097-104.

[50] Touil YS, Auzeil N, Boulinguez F, et al. Fisetin disposition and metabolism in mice: Identification of geraldol as an active metabolite. Biochem Pharmacol 2011; 82(11): 1731-9.

[51] Howitz KT, Bitterman KJ, Cohen HY, et al. Small molecule activators of sirtuins extend Saccharomyces cerevisiae lifespan. Nature 2003; 425(6954): 191-6.

[52] Nasello AG, Vanzeler MLA, Felicio LF. A comparison of bromopride and domperidone effects on rat conditioned avoidance and motor activity. Pharmacol Toxicol 1991; 68(1): 46-50.

[53] Niemegeers CJE. Anti-emetic specificity of dopamine antagonists. Psychopharmacology 1982; 78(3): 210-3.

[54] Hsiang YH, Hertzberg R, Hecht S, Liu LF. Camptothecin induces protein-linked DNA breaks via mamalian topoisomerase-I. J Biol Chem 1985; 260(27): 4873-8.

[55] Slichenmyer WJ, Rowinsky EK, Donehower RC, Kaufmann SH The current status of camptothecin analogs as antitumor agents. J Natl Cancer Inst 1993; 85(4): 271-91.

[56] Guzman ML, Rossi RM, Karnischky L, et al. The sesquiterpene lactone parthenolide induces apoptosis of human acute myelogenous leukemia stem and progenitor cells. Blood 2005; 105(11): 4163-9.

[57] Honkanen RE. Cantharidin, another natural toxin that inhibits the activity of serine threonine protein phosphatases type- 1 and type2a. FEBS Lett 1993; 330(3): 283-6.

[58] Matsakas A, Patel K. Skeletal muscle fibre plasticity in response to selected environmental and physiological stimuli. Histol Histopathol 2009; 24(5): 611-29.

() Nierobisz et al.; Licensee Bentham Open.

This is an open access article licensed under the terms of the Creative Commons Attribution Non-Commercial License (http://creativecommons.org/licenses/by-nc/3.0/) which permits unrestricted, non-commercial use, distribution and reproduction in any medium, provided the work is properly cited. 